\title{
Lawyers Asleep at the Wheel? The GM-Fisher Body Contract
}

Abstract. In the analysis of vertical integration by contract versus ownership one event has dominated the discussion-General Motors' merger with Fisher Body in 1926. The debates have all been premised on the assumption that the ten-year contract between the parties signed in 1919 was a legally enforceable agreement. However, it was not. Because Fisher's promise was illusory the contract lacked consideration. This note suggests that GM's counsel must have known this. It raises a significant question in transactional engineering: what is the function of an agreement that is not legally enforceable. 


\title{
Lawyers Asleep at the Wheel? The GM-Fisher Body Contract
}

\author{
Victor P. Goldberg
}

Oh no! Not another paper on the GM-Fisher Body-did-holdup-make-them-do-it battle. Not quite. I want to go back one step to reexamine one matter that none of the combatants has questioned. They have all focused on the question: why was there a transition from the ten-year, exclusive contract to vertical integration? The underlying assumption of all the participants in the Fisher wars was that the contract was a legally enforceable document. It wasn't. A court back in 1919 (and most likely even today) would have found Fisher's promise illusory and the contract, in the language of the day, a nudum pactum.

Until recently the debate went on without access to the actual contract, with the various authors relying primarily on the characterization of the contract in executives' testimony in the DuPont-General Motors antitrust trial in the1950's. ${ }^{1}$ After the spate of articles appeared in 2000, Ben Klein obtained a copy of the original contract. Neither he nor Ronald Coase, who also wrote after obtaining access to the contract, questioned whether the contract was legally enforceable. The non-enforceablity of the contract adds a new wrinkle to the story. If a longterm contract is an intermediate point on a continuum from spot contracting to full integration, where on that continuum does an unenforceable contract fit? Why is it different from no contract at all?

The debate, recall, concerns Klein's argument that hold-up issues induced the parties to switch from a long-term contract (vertical integration by contract) to full-fledged vertical integration (integration by ownership). In 1919, GM took a sixty percent ownership share in Fisher and entered into a ten-year manufacturing contract, characterized as an exclusive dealing contract. Fisher manufactured closed bodies. There is general agreement that the rapid growth of the closed body share of the auto market meant that the arrangement was very profitable and that the cost-plus pricing formula resulted in a large share of those profits going to Fisher. There is also general agreement that in 1926 there was a dispute over the location of a new Fisher plant, with GM wanting it proximate to its Buick plant in Flint, and Fisher desiring a less GM-specific location in Detroit, where it would have better access to other car manufacturers. Following the merger in 1926, the Detroit plant was closed.

Klein claims that Fisher's relative success in the early 1920's involved a hold-up by Fisher and that the merger in 1926 involved Fisher's fear that co-location of the new Buick plant would make it vulnerable to hold-up by GM. Klein's critics-notably Coase-agree on the basic facts, but disagree about the hold-up characterization. I do not intend to engage this question. My purpose in this brief paper is to shed light on a peripheral matter-to show that the alternative to vertical integration in this case was not, as the literature presumes, a preexisting legally enforceable contract.

The assumption that the agreement was legally enforceable plays a role (albeit not the

${ }^{1}$ Cite. In addition, some contemporaneous documents. Cite. 
central role) for many of the protagonists. ${ }^{2}$ Herein, a sampling:

- $\quad$ Since GM was contractually obligated to buy all of its automobile bodies from Fisher for a period of 10 years, GM could not threaten to move its demand to another supplier, and Fisher's specific investments were protected against GM's hold-up threat. Klein (2000, p. 108)

- $\quad$ With regard to the Fisher Body supply holdup in 1925-26, the court presumably would have enforced the imperfect long-term, exclusive dealing contract that locked in GM, thereby permitting Fisher to engage in a holdup by not making the desired investments and by charging GM relatively high body prices. Klein (2000, p. 125)

- The only way GM could opt out of not performing to the literal imperfect terms of the long-term Fisher Body contract, that is, not continuing to buy bodies at cost-plus from improperly located plants until the contract expired in 1929, was to declare bankruptcy. Klein (2000, p. 130)

- $\quad$ The exclusive contract meant that General Motors could not counter-threaten in its negotiations with Fisher Body that it would use an alternative body manufacturer to supply co-located body capacity at its Chevrolet assembly facilities if it did not reach agreement with Fisher Body. Klein (2007, p.26)

- However, Fisher Body was largely protected against a General Motors holdup risk at least for the next seven years, by the exclusive dealing contract that remained in effect. Klein (2007, p. 36)

- $\quad$ Presumably, Coase believes that G.M.'s potential to hold up Fisher Body after Fisher made large G.M.-specific capacity investments was prevented entirely by Fisher Body's threat of a reputational sanction. But if the loss of future business was sufficient to prevent General Motors from holding up Fisher Body after Fisher Body made its G.M.specific investments, why then did General Motors commit to an exclusive purchasing arrangement with Fisher Body? The exclusive significantly tied G.M.'s hands in terms of its bargaining power with regard to possible contractual adjustments that might have to be made over the ten years of the contract, a constraint that, as we shall see, later created serious economic difficulties for General Motors. Klein (2007, p. _ )

- $\quad$ For example, the statement about Fisher Body using inefficient methods of production was without question untrue. The contract stated that Fisher Body "will use the most modern, efficient and economical methods machinery and devices consistent with good workmanship. ...”. . . Had Fisher Body in fact used an inefficient method of production GM's engineering staff would have detected it and their law department would have taken steps to enforce the terms of the contract. Coase (2006, p. 266)

${ }^{2}$ Williamson (1992, p. 285), who often invokes the Fisher Body example, also puts a lot of weight on legal enforceability: “[I]dentical disputes within 'make' transactions (internal procurement) and 'buy' transactions (outside procurement) are treated differently-in that the courts will hear the one and will refuse to be drawn into the resolution of the other." (Emphasis in original) 
- The contracting relation between General Motors and Fisher Body thus moved through three stages. More or less autonomous contracting evidently worked to the satisfaction of the parties in the wooden body era. Specialized physical assets were needed, however, to support the distinctive body designs that attended the shift to the metal body era. A condition of greater bilateral dependency thereby resulted. Efficient contracting principles required that a new contracting structure be crafted in response. Price adjustment by formula and dispute settlement by arbitration were thus expressly provided. Williamson (1985, p. 115)

- $\quad$ Clearly Fisher Bodies would have lost a considerable part of the value of its investments if it had left General Motors for another car maker. Therefore a contract signed in 1919 gave Fisher Bodies a ten-year exclusive dealing clause to protect it from being held up by General Motors. On the other hand, this gave Fisher Bodies the possibility of raising prices outrageously; to prevent this, the contract also contained a cost-plus clause. Salanié (1997, p. 181)

- Moreover, because the 1919 contract guaranteed that Fisher would meet all of GM's closed-body needs, it effectively gave GM precedence over other customers, especially Ford. Freeland (2000, p. 42)

If, as I argue, the contract was not enforceable, then all these statements are wrong. The contract language does not affect the legal obligations of either party (with one exception). As a matter of law, could Fisher favor Ford over GM? Could it refuse to produce any bodies for GM? Could GM buy bodies from whomever it wanted? Could GM insist on a flat rate from Fisher, rather than the cost-plus pricing? Was GM's only recourse to declare bankruptcy? Was Fisher obligated to build “efficient” plants? Yes, Yes, Yes, Yes, No, and a qualified No. As long as there was no enforceable agreement, the contract language did not bind either party going forward. Even if the executives acted as if they were unaware of this, their counsel surely knew. In the next section I will first present the actual contract language. I will then show why the document was clearly not enforceable.

I.

Fisher Body and General Motors entered into two agreements in 1919. In the first, GM bought a $60 \%$ interest in Fisher. A voting trust was put in place for the first five years, preventing GM from taking control. The second was the manufacturing agreement. It had a ten year term and has been characterized by Klein and the others as an "exclusive dealing" agreement. I reproduce the relevant portions of the agreement here.

ARTICLE I. GENERAL MOTORS will order and purchase from the FISHER COMPANY substantially all the automobile bodies, both open and closed, required by it which the FISHER COMPANY can furnish, of the kind, quantity, and at the times specified by GENERAL MOTORS, excepting, however, such automobile bodies as GENERAL MOTORS may build in its own manufacturing plant or plants of allied organizations and corporations existing at the date of this agreement; ... . Subsequent to the date hereof GENERAL MOTORS will not enter 
into or renew agreements with third parties for bodies required by it, (except as herein provided).

ARTICLE II. GENERAL MOTORS will from time to time furnish to the FISHER COMPANY schedules showing the kind and quantity of the automobile bodies to be furnished by the FISHER COMPANY, which said schedules shall be accompanied by the specifications in accordance with which the said bodies are to be built. The schedules shall also specify the times and places at which, and the quantities in which, bodies are to be delivered by the FISHER COMPANY to GENERAL MOTORS, and shall be furnished reasonably in advance of requirement.

ARTICLE III. The FISHER COMPANY will immediately upon the receipt of the schedule from time to time to be furnished by GENERAL MOTORS, notify said GENERAL MOTORS of its acceptance in whole or in part of the orders for automobile bodies contained in said schedules. In the event that the FISHER COMPANY accepts the orders specified in the schedules from time to time furnished by GENERAL MOTORS, it shall proceed to make and deliver the automobile bodies called for by said schedules in accordance with the plans and specifications supplied by GENERAL MOTORS, and in such a way as to enable it to comply with the schedule of deliveries furnished to it by GENERAL MOTORS. The FISHER COMPANY will use its best efforts to make and deliver all the automobile bodies covered by schedules accepted by the FISHER COMPANY, and to that end will use the most modern, efficient and economical methods, machinery and devices consistent with good workmanship in the production of said automobile bodies. ... In the event that the FISHER COMPANY is unable through lack of facilities or for other reasons to furnish the automobile bodies in accordance with the schedules supplied by GENERAL MOTORS it shall immediately upon receipt of such schedules notify GENERAL MOTORS of its inability to furnish the automobile bodies called for in such schedule in whole or in part, and thereupon GENERAL MOTORS shall have the right to place orders for such automobile bodies elsewhere.

ARTICLE IV. If the FISHER COMPANY by rejection of the schedules of orders furnished to it by GENERAL MOTORS, or by its failure to make deliveries as specified, should be unable to furnish automobile bodies to such extent as to interfere materially with the general program of automobile production mapped out by GENERAL MOTORS, then GENERAL MOTORS, in addition to the remedies provided above, may, at its option purchase, or cause to be constructed plant facilities for the production of automobile bodies, and thereafter be able to furnish the additional automobile bodies made by the plant or plants thus acquired.

To summarize, General Motors promises to order and purchase substantially all its car bodies from Fisher (Article I). It promises to provide schedules of its needs to Fisher in a timely fashion (Article II). So far, so good. What does Fisher promise? After receipt of the schedules, Fisher promises to tell General Motors whether or not it will accept the orders (Article III). If it

Page -4- 
accepts, then Fisher has an obligation to use its best efforts to fill the orders (Article III). That obligation entails Fisher's using modern and efficient means (Article III). Fisher could reject GM orders "through lack of facilities or for other reasons" (Article III). Nothing precluded Fisher from selling some, or all, of its body production to Ford. Indeed, the contract presumed that Fisher would be selling some of its output to other companies. ${ }^{3}$ General Motors' options if Fisher were to choose not to fill orders are spelled out in Articles III and IV.

The key is that Fisher has not promised to do anything. It could choose to fill orders or not, and the contract placed no limits on its discretion ("for other reasons"). Fisher's promise was "I will do it if I want to." And that is not enough to make the contract enforceable. The law was clear that such a promise was illusory; there was no consideration and, therefore, neither party would be legally bound. The law was spelled out in two contemporaneous treatises.

If A. offers to supply at a certain price such goods as B. may order, and B. promises to pay at that price for such goods as he may order, there is, of course, no contract, for B has not promised to order any goods, and it is optional with him whether his promise to pay shall ever come into effect. Both parties must be bound or neither is bound; in other words, there must be mutuality of engagement. Clark (1914, §70)

[Illusory promises are insufficient consideration.... The insufficiency of such a promise is most commonly illustrated in agreements to buy or sell goods where the quantity is fixed by the wishes of one of the parties. A promise to buy such a quantity of goods as the buyer may thereafter order, or to take goods in such quantities "as may be desired," or as the buyer "may want" is not sufficient consideration, since the buyer may refrain from buying at his option and without incurring legal detriment himself or benefiting the other party. Williston (1920, $\S 104)$.

The legal treatment of illusory promises became more complicated after Cardozo's opinion in Wood v. Lucy, Lady Duff Gordon in December, 1917. ${ }^{4}$ I will return to that case shortly, but first I want to emphasize the importance of the illusory contract doctrine to the auto industry. In the years before the Fisher-GM contract, a number of agreements between auto manufacturers and their dealers were held to be illusory and, therefore, unenforceable. Ford's dealership agreements in the 1920's and '30's were deliberately designed to be unenforceable.

\footnotetext{
${ }^{3}$ ARTICLE X. In the event that the FISHER COMPANY shall manufacture and sell to third parties automobile bodies similar in grade to those furnished to GENERAL MOTORS at or about the same time but at a price less than the amount paid by GENERAL MOTORS therefore, viz: the cost of said bodies and (17.6\%) Seventeen and Six Tenths Per Cent. in addition thereto, then said GENERAL MOTORS shall be obligated to pay for such similar grade of automobile bodies made at or about the same time only the price charged by the FISHER COMPANY to third parties, and any over-payment in respect thereto shall be refunded by the FISHER COMPANY.

${ }^{4}$ Cite.
} 
In 1912, the Seventh Circuit held that one-year, exclusive territory contracts for dealerships were not enforceable in two separate cases. In Velie Motor Car Co. v. Kopmeier Motor Car Co. ${ }^{5}$ it held against the manufacturer-plaintiff, saying that the "plaintiff did not obligate itself to sell and deliver to defendant any automobiles. It virtually reserved the right to do nothing at all. Defendant had the right to sell to its customers, but was entirely at the mercy of plaintiff when it came to filling the order.” (p. 330)

Later that year, in Oakland Motor Car Co.v.Indiana Automobile Co., ${ }^{6}$ the court cited Velie in holding for the manufacturer. The contract stated that any order sent in by the dealer shall not be "binding upon said manufacturer" unless accepted by it "at least 30 days prior to date for delivery." ( p.503) The court noted that "it is frankly conceded in the brief on behalf of plaintiff 'that a contract for future delivery of personal property, which confers upon either party the arbitrary right of cancellation prior to the delivery, would be lacking in mutuality,"” (p. 504) and would therefore be unenforceable.

The following year, a New York court in Goodyear V. H. J. Koehler Sporting Goods Co. ${ }^{7}$ refused to enforce a contract for the sale to a dealer of Hupmobiles: "By this clause it was left entirely optional with defendant whether or not it would deliver any automobiles at all, and if it refused to deliver any it became subject to no penalty or damages. It seems to me that it would be difficult to find a clearer case of a contract imposing an obligation on one party, and no obligation whatever on the other.” (p. 1047) The entire agreement was, therefore, void.

Finally, some two weeks after GM and Fisher signed their agreement, a Nebraska court refused to enforce a similar exclusive contract: "The defendant did not obligate itself to sell, nor plaintiff to buy, any specified quantity of automobiles, nor was a determinable quantity fixed in a mutually binding way by the requirements of an established business. The defendant was expressly exempted from such an obligation and from adherence to the schedule of prices and discounts set forth. It was free to decline shipments under the contract, and also free to fix and change prices at will. ... It is quite manifest that the contract merely furnished a basis for future dealings to be observed no longer than was mutually satisfactory. There was no hard and fast commitment of either party, if he chose to break away."8

I must emphasize two points. First, the rule in these cases is that either both parties are bound or neither is. That is, if Fisher is free not to supply auto bodies if it so decides, then GM, despite the specific promises made in the contract, has no obligations; it is free to buy auto bodies from other suppliers. Second, the rule only applies to the executory (forward-looking)

${ }^{5} 194$ F. 324 ( $7^{\text {th }}$ Cir. 1912). The Velie was an automobile brand from 1908 to 1929. The company was founded by and named for Willard Velie, a grandson of John Deere. (Wikipedia)

${ }^{6} 201$ F. 499 (7 $7^{\text {th }}$ Cir.1912). Oakland was sold to General Motors in 1909.

${ }^{7} 159$ A.D. 116, 143 N.Y.S. 1046 (1913).

${ }^{8}$ Huffman v. Paige-Detroit Motor Co., (C. C. A. 8th) 262 F. 116, 117. Paige sold high-end luxury cars between 1908 and 1927. (Wikipedia)

Page -6- 
part of the contract. If a dealer ordered a car and the manufacturer agreed to ship it, then the contract terms would apply. Likewise, if Fisher accepted one of GM's orders, then it would be bound to use its best efforts to make and deliver the bodies and would also be bound by the costplus formula. (This is the basis for my “qualified no,” above.) The best efforts proviso would have had no effect on Fisher's decisions on co-locating its body plants with GM plants, except for the unlikely possibility that the plant construction decision was in response to a specific GM order.

Not all auto dealer contracts in that era were void for want of consideration. It was clear, however, that one choice open to the auto companies was to design their dealership contracts so that they would not be legally enforceable. The standard Ford dealership, according to Kessler (1957, p.1151), was unenforceable from 1921 into the 1930's. It is hard to imagine that a GM lawyer in 1919 could have been unaware of this. When negotiating the Fisher deal, they knew what was necessary to make an agreement enforceable, and it appears that they chose not to do so.

Prior to Cardozo's decision in Wood v. Lucy, Lady Duff Gordon, the black letter law was quite clear: an illusory promise was not enforceable. Cardozo found a way to overcome precedent and find consideration, despite the fact that one party, Wood, had literally promised to do nothing, much as Fisher Body had. However, given the facts of Wood and the language in the Fisher-GM contract, it would have been extremely unlikely that a court could use the Wood precedent to find the Fisher contract enforceable. The factors that enabled Cardozo to surmount the illusory promise hurdle were not present in the GM-Fisher contract.

Wood had an exclusive, one-year contract to place endorsements for Lucy; if he placed an endorsement, they would share the proceeds 50:50. ${ }^{9}$ After Lucy entered into some endorsement agreements bypassing Wood, he sued. Her defense was that he had only promised to share revenues if he happened to drum up some business, but he did not actually promise to drum up the business. The agreement therefore, she argued, lacked consideration and was not enforceable. Appellate Division so held in a unanimous opinion. In a 4-3 opinion, Cardozo reversed. He conceded that the agreement did not include an enforceable promise, but he supplied the consideration by implying a duty to use "reasonable efforts." He put particular weight on her vulnerability-if Wood did nothing, Lucy would receive no endorsement income for the life of the contract. Because of this vulnerability, a duty to use reasonable efforts could be implied.

Whether the analysis was correct is beside the point. The crucial factors to avoid the "no consideration/no contract" result were her vulnerability and the implication of reasonable efforts. Even if Wood v. Lucy was recognized as putting a major dent in the doctrine (not clear, since there were no appellate decisions citing Wood prior to the signing of the Fisher-GM contract), the Fisher-GM contract would still fail the test. ${ }^{10}$ If Wood did nothing, Cardozo claimed that

${ }^{9}$ For a more thorough analysis of Wood, see Goldberg (2006, ch.2).

${ }^{10}$ The first New York case to cite Wood was decided almost two years after the FisherGM contract was signed. The court found that agreement unenforceable; Oscar Schlegel

Page -7- 
Lucy was helpless. Not so, GM. If Fisher accepted no orders, General Motors could place orders elsewhere (Article III); indeed, if Fisher's failure to supply bodies was of sufficient magnitude, GM could build or acquire a body plant. GM was far from helpless (at least on paper). Moreover, the most plausible interpretation of the contract would preclude implying any level of effort. After all, the contract did contain an explicit "best effort" clause, but with a specified, narrow domain. It applied only if Fisher had accepted an order. "The FISHER COMPANY will use its best efforts to make and deliver all the automobile bodies covered by schedules ...” (Article III) It would have been easy enough to make the efforts requirement (best or reasonable) apply to the first sentence of Article III. In most jurisdictions that would have been enough to make the contract enforceable. ${ }^{11}$ Its presence in the clause and its absence in that first sentence suggest a deliberate choice by the drafters.

II.

Counsel should, therefore, have known when drafting the agreement that it would not be enforceable. Even if, somehow, the lawyers were unaware in 1919 that their agreement was illusory, if a serious dispute arose prior to the 1926 merger, a minimally competent attorney would have had to conclude that there was no enforceable contract. While counsel should have known, the evidence suggests that the clients were unaware. Fisher's letter to shareholders recommending the merger indicates a belief that the contract was valid:

In 1919 General Motors acquired a sixty per cent (60\%) interest in the common stock of Fisher Body and at the same time entered into a ten-year contract for its automobile body requirements. As you are aware, this contract has been exceedingly profitable to Fisher Body, and at the present time about $90 \%$ of its business consists of bodies made for General Motors . . . . As the contract made with General Motors in 1919 has but a relatively short term remaining, your officers and directors have given serious thought to the future prospects of Fisher Body. In 1929 a new contract must be negotiated, or General Motors will be free either to build its own bodies or purchase them elsewhere. ${ }^{12}$

Alfred Sloan's (General Motor's president throughout the period) deposition testimony three decades later in the DuPont-General Motors case strongly hints at a belief that the

Manufacturing Company v. Peter Cooper's Glue Factory 231 N.Y. 459; (1921). For an analysis of Schlegel, see Goldberg (2006, ch. 3). In his 1920 treatise, Williston mentions Wood v. Lucy, but only as a "see also." If the case signaled a revolution as many commentators suggest, the revolution was slow in coming.

${ }^{11}$ Remarkably, some jurisdictions find implied best efforts clauses enforceable, while holding that express best efforts clauses are unenforceable. See Goldberg (2006, p. 69).

${ }^{12}$ Letter from Board of Directors of Fisher Body Corporation to the Stockholders of Fisher Body Corporation (May 17, 1926), Gov't Trial Ex. No. 506, Du Pont, 126 F. Supp. 235. Reproduced in Klein (2000, fn 46, p.119 
agreement was legally enforceable:

Q. Do you recall whether or not a contract was entered into at that time between Fisher Body and General Motors regarding the production of closed bodies?

A. Yes, there was a contract made. I never saw the contract, but my understanding is that it was a cost-plus contract. In other words, Genera Motors paid Fisher the cost of production, plus a profit, and subject to correction, I have always understood that that profit, the profit so established, was $17 \frac{1 / 2}{2}$ per cent over cost. ${ }^{13}$

The puzzling question is this: why, if GM was unhappy with the deal, did management not care enough to ask their counsel if GM was indeed bound by the manufacturing contract? The start of an answer is that they were not that unhappy. Things never got so bad that they were willing to risk rupturing the entire relationship. What made GM adhere to a legally unenforceable contract? Its 60\% ownership of Fisher? Its desire to keep the Fisher brothers happy, given its long-term interest in integrating them into the firm ${ }^{14}$ Its vulnerability to a Fisher threat to cut off supply?

Regardless of whether the agreement was legally enforceable, it provided a yardstick or reference point ${ }^{15}$ against which either party's behavior could be judged. If either party simply walked away, both would have suffered significantly. That does not, however, provide a complete explanation. It might explain why the parties avoided the equivalent of nuclear war, but it does not answer more subtle questions. Why honor the specific terms (particularly the cost-plus formula)? Why, and how, do reference points get modified?

Chandler and Salsbury (1971) provide one example of a modification, although the facts are somewhat unclear. They claim that the pricing formula was revised in 1924, with GM increasing its relative share of the profits. "[I]nstead of a cost plus contract, its profits would be computed in the same manner as those of the operating divisions. ... [The new formula] was put into effect by the end of October 1924.” (1971, p. 576). They claim that the original contract expired after five years and that the new formula was agreed upon after it had expired. ${ }^{16}$ However, the manufacturing contract would not have expired. What had expired was the restriction on GM's ability to vote its 60\% holding of Fisher. It is not clear why that would affect the pricing formula, but not other aspects of the relationship (like the decision of where to locate the new Buick body plant).

This is not the place to examine the details. My goals in this brief paper are modest. My first goal was to show that the participants in the Fisher GM debate have mischaracterized the

${ }^{13}$ March 9, 1953. [p. 2908]

${ }^{14} \mathrm{By} 1925$, three of the Fisher brothers were y on its board of directors and two were officers. Source: Material collected by Richard Brooks from General Motors Annual Reports..

${ }^{15}$ See Hart \& Moore (2006).

16“"By 1924, when the contract expired, Pierre [DuPont], as well as the Fishers, realized how much conditions had changed.” (1971, p. 575).

Page -9- 
pre-merger world: There was no legally enforceable agreement. That was easy to show. My second point is to provide one data point demonstrating that parties can intentionally draft agreements that are not legally enforceable, and these agreements can significantly affect their subsequent behavior. The pre-1926 behavior of Fisher and GM illustrates this. I have only indicated that the unenforceable agreements can be effective; I have not provided an explanation of when they will be used, how they work, and under what circumstances they would succeed or break down. If, as I suspect, such agreements are fairly common, any serious theory of the organization of economic activity will have to take this mechanism into account. 